\title{
Article \\ Modified Camellia oleifera Shell Carbon with Enhanced Performance for the Adsorption of Cooking Fumes
}

\author{
Dongliang Liao ${ }^{1}$, Wen Shi ${ }^{2}$, Jing Gao ${ }^{2}$, Bin Deng ${ }^{3,4, *}$ and Ruijin $\mathrm{Yu}^{2, *}$ \\ 1 College of Natural Resources and Environment, Northwest A\&F University, Yangling 712100, China; \\ ld119990923@163.com \\ 2 College of Chemistry \& Pharmacy, Northwest A\&F University, Yangling 712100, China; \\ wznln@nwafu.edu.cn (W.S.); Sven@nwafu.edu.cn (J.G.) \\ 3 College of Chemistry \& Biology and Environmental Engineering, Xiangnan University, \\ Chenzhou 423043, China \\ 4 Hunan Provincial Key Laboratory of Xiangnan Rare-Precious Metals Compounds Research and Application, \\ Chenzhou 423043, China \\ * Correspondence: ddhbyjs@126.com (B.D.); yuruijin@nwsuaf.edu.cn (R.Y.); Tel./Fax: +86-0735-2865916 (B.D.); \\ +86-29-87092226 (R.Y.)
}

\begin{abstract}
Using Camellia oleifera shell (COS) as a raw material and phosphoric acid as the activator, activated Camellia oleifera shell carbon (COSC-0) was prepared and then modified by Fenton's reagent (named as COSC-1). SEM, GC-MS, FTIR, and specific surface area and pore analyzers were used to study the adsorption performance of COS, COSC-0, and COSC-1 on cooking fumes. Results showed that COSC- 1 was the best adsorbent compared with COS and COSC-0. The adsorption quantity and penetrating time of COSC- 1 were $44.04 \mathrm{mg} / \mathrm{g}$ and $4.1 \mathrm{~h}$, respectively. Most aldehydes could be adsorbed by COSC-1, which was due to the large number of carbonyl and carboxyl groups generated on the surface of COSC- 1 from the action of Fenton's reagent. The adsorption effect of COSC-1 on different types of pollutants in cooking fumes was analyzed based on the similar compatibility principle. COSC-1 showed a much higher adsorption effect on the strong polarity functional groups than on weak polar groups. The results provide a theoretical basis for the application of Camellia oleifera shell carbon adsorption technology in the treatment of cooking fumes.
\end{abstract}

Keywords: cooking fumes; modification; carbon from Camellia oleifera shell; adsorption performance

Academic Editor: Maria Filipa Ribeiro

Received: 13 April 2021

Accepted: 11 May 2021

Published: 20 May 2021

Publisher's Note: MDPI stays neutral with regard to jurisdictional claims in published maps and institutional affiliations.

\section{Introduction}

Cooking fumes from the Chinese catering industry contain numerous carcinogenic substances such as aldehydes and polycyclic aromatic hydrocarbons (PAHs) [1-3]. Recently, research on female non-smokers showed that people tend to suffer lung cancer due to the polymorphism of human genes and the interaction of fumes [4-7].

In the last decade, biological washing and catalyst combustion have been successfully applied in the field of cooking fume purification [8,9], but complicated operating conditions and expensive cost are their main disadvantages. Thus, a simple and effective method to degrade and treat cooking fumes has become an urgent need. Activated carbon (AC) is widely applied in dealing with waste gas due to its unique properties, such as good pore structures and high specific surface areas $[10,11]$. Recently, AC has become a popular material because many solid wastes such as straws [12,13], nut shells [14-17], almond shells [18-21], and bagasse [22,23] can be utilized to prepare AC [1].

Camellia oleifera shell (COS) is an important byproduct in processing woody edible oil. Approximately 0.54 tons of COS can be produced from 1 ton of Camellia oleifera nuts, and their main components are cellulose, hemicellulose, and lignin; thus, COS is an ideal source for the preparation of AC [24]. In recent years, many researchers have successfully prepared AC using COS and explored its adsorption performance by using different preparation methods. For instance, Sun et al. [25] used phosphoric acid as an activator and 
microwave heat to prepare AC from the oil of camellia nut shells, and the adsorption for methylene blue reached $330 \mathrm{mg} / \mathrm{g}$. Zheng et al. [26] prepared an adsorbent by pyrolysis carbonization followed by the potassium hydroxide $(\mathrm{KOH})$ activation of $\mathrm{COS}$ under the nitrogen atmosphere; this $C$. oleifera shell activated carbon adsorbent can effectively adsorb hexavalent chromium ( $\mathrm{Cr}(\mathrm{VI}))$ from aqueous solution. Zirconium dioxide-biochar $\left(\mathrm{ZrO}_{2} / \mathrm{BC}\right)$, with excellent fluoride adsorption properties, was also successfully prepared by calcining the zirconium-impregnated byproduct from Camellia oleifera (C. oleifera) seed shell in a one-step method [27]. Therefore, Camellia oleifera shell carbon (COSC) has attracted increasing attention as a promising material in chemical engineering and environmental science because of its large surface area, large pore size, and high stability. However, studies on COSC for the adsorption of cooking fumes are limited. In this research, an AC from COS modified with Fenton's reagent for the treatment of cooking fumes was reported for the first time.

\subsection{Preparation and Modification of COSC}

In a typical experimental procedure, COS taken from the countryside of Ningdu, Jiangxi Province of China was first cleaned with water and dried in an oven at $12{ }^{\circ} \mathrm{C}$ for $12 \mathrm{~h}$. Then, the dried COS was added into $60 \%$ of phosphoric acid solution at a weight ratio of 1:3. The mixture was placed into a box-type resistance furnace for carbonization and activation at $500{ }^{\circ} \mathrm{C}$ for $2 \mathrm{~h}$ with a heating rate of $10{ }^{\circ} \mathrm{C} \mathrm{min}-1$. When it cooled down to room temperature, the product was collected and washed with deionized water until the $\mathrm{pH}$ of the solution was close to neutral. Finally, the product was dried and stored in a sample bag named COSC-0.

Fenton's reagent was prepared from a solution of $\mathrm{FeSO}_{4} \cdot 7 \mathrm{H}_{2} \mathrm{O}(0.5 \mathrm{~mol} / \mathrm{L})$ and $\mathrm{H}_{2} \mathrm{O}_{2}$ (30\%) with the molar proportion of $\mathrm{n}(\mathrm{Fe}): \mathrm{n}\left(\mathrm{H}_{2} \mathrm{O}_{2}\right)=1: 10$, and the $\mathrm{pH}$ value of the solution was adjusted to 3 with $0.1 \mathrm{~mol} / \mathrm{L} \mathrm{H}_{2} \mathrm{SO}_{4}$ solution. The COSC- 0 was immersed in Fenton's reagent and left overnight at room temperature. The obtained product was washed with deionized water to neutral and dried at $50^{\circ} \mathrm{C}$ in the oven, and the corresponding samples were denoted as "COSC-1."

\subsection{Concentration Measurement of Pollutants from Cooking Fumes}

As shown in Figure 1, the samples of simulated cooking fumes (SCFs) were collected for $3 \mathrm{~min}$ in the inlet and outlet with sampling tubes filled with $5 \mathrm{~g}$ of granular AC; sampling was repeated three times. The granular AC in the sample tube was removed, transferred into a flask, and washed with $15 \mathrm{~mL}$ of carbon tetrachloride for $5 \mathrm{~min}$ by using an ultrasonic device (Hangzhou Boke Ultrasonic Equipment Co., LTD, Hangzhou, Zhejiang, China). The cleaning liquid was collected and transferred into another flask (marked as " $\mathrm{A}$ "). The granular $\mathrm{AC}$ was washed once more with $10 \mathrm{~mL}$ of carbon tetrachloride, and the cleaning liquid was also collected and transferred into flask A.

According to the standard curve, the pollutant concentration of SCFs in the collected cleaning liquid $\left(\rho_{0}\right)$ was measured with a CY-2000 multi-functional IR oil content analyzer. The pollutant concentration of SCF samples $\left(C_{0}\right)$ could be calculated by the following equation:

$$
C_{0}=\left(60 \times \rho_{0} \times \mathrm{V}\right) \div(\mathrm{Q} \times \mathrm{t})
$$

where $C_{0}$ is the pollutant concentration of the sample, $\mathrm{mg} / \mathrm{m}^{3} ; \rho_{0}$ is the pollutant concentration of SCFs in the collected cleaning liquid, $\mathrm{mg} / \mathrm{L} ; \mathrm{V}$ is the volume of cleaning liquid, $\mathrm{L}$; $\mathrm{Q}$ is the gas flow, $\mathrm{m}^{3} / \mathrm{h}$; and $\mathrm{t}$ is the sampling time, $\min$. 


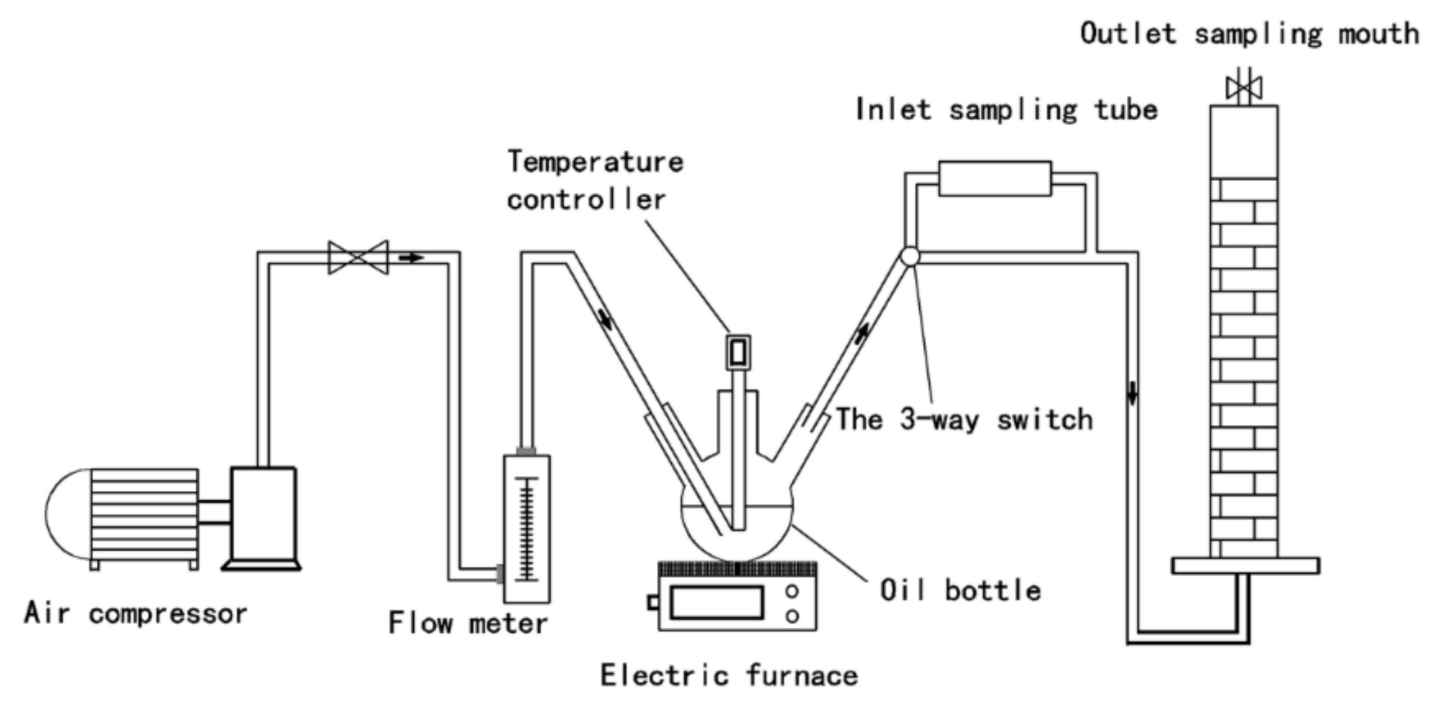

Figure 1. Schematic of experimental apparatus for treating cooking fumes by COS, COSC-0, and COSC-1.

\subsection{Measurement of Adsorption Capacity}

To measure the adsorption capacity of different adsorbents for cooking fumes, a fixed adsorbing tower was set up and filled with a $30 \mathrm{~cm}$ thick adsorbent. The inlet concentration of SCFs was $90 \mathrm{mg} / \mathrm{m}^{3}$, the gas hour space velocity (GHSV) was $4300 / \mathrm{h}$, the temperature was $25 \pm 5^{\circ} \mathrm{C}$, and the outlet samples of SCFs were collected at different times. Breakthrough curves of different adsorbents for SCFs were drawn with adsorption time as the abscissa and outlet concentration of SCFs as the ordinate. The outlet concentration of $2.0 \mathrm{mg} / \mathrm{m}^{3}$ acted as the penetration concentration of SCFs, based on GB18483-2001 in China, and the corresponding adsorption time and adsorption quantity are described as penetration time and penetration adsorption quantity. Moreover, the saturation act time was the adsorption time when the proportion of outlet and inlet concentrations of cooking fumes was $95 \%$. Through graphing software of Origin 9.0 (Origin Lab), the penetration adsorption quantity of cooking fumes could be calculated from the integral area (S) between the penetration curves and abscissa:

$$
q=(C \times t-S) \times \mu \times A \times 3600 \div M
$$

where $q$ is the equilibrium adsorption quantity of adsorbents for cooking fumes, $\mathrm{mg} / \mathrm{g}$; $C$ is the inlet concentration of cooking fumes, $\mathrm{mg} / \mathrm{m}^{3} ; t$ is the adsorption time, $\mathrm{h} ; \mu$ is the velocity of the bed layers, $\mathrm{m} / \mathrm{s} ; A$ is the sectional area of adsorption tower, $\mathrm{m}^{2}$; and $M$ is the weight of adsorbents, $g$.

\subsection{GC-MS Analysis of Organic Contents in Cooking Fumes}

GC conditions: The chromatographic column was an Elite-5MS capillary column $(30 \mathrm{~m} \times 0.25 \mathrm{~mm}, 0.25 \mu \mathrm{m})$. The carrier gas was helium with a flow rate of $1 \mathrm{~mL} / \mathrm{min}$. The collision gas was argon with a temperature of $250^{\circ} \mathrm{C}$, flowing amount of $1 \mu \mathrm{L}$, and division ratio of $10: 1$. The column box was maintained at $50^{\circ} \mathrm{C}$ for $2 \mathrm{~min}$, programmed at $8{ }^{\circ} \mathrm{C} / \mathrm{min}$ to $250{ }^{\circ} \mathrm{C}$, and held at $250{ }^{\circ} \mathrm{C}$ for $12 \mathrm{~min}$.

MS conditions: The injector temperature was $250^{\circ} \mathrm{C}$. The electric impact energy of EI ion source was $70 \mathrm{eV}$. The mass scanning range was $40-550 \mathrm{~m} / \mathrm{z}$. The delaying time for solvent was $3 \mathrm{~min}$.

\subsection{Characterization}

The morphology of the samples was investigated by scanning electron microscopy (SEM) (S-4800, Hitachi, Japan). FTIR was used to characterize and analyze the framework and functional groups of samples. The scanning range was from $400 \mathrm{~cm}^{-1}$ to $4000 \mathrm{~cm}^{-1}$. 
The specific surface area and pore structure of samples were determined on a NOVA1200e Surface Area Analyzer (NOVA1200e, Quantachrome, America) at 77.4 K. All samples were heated at $120^{\circ} \mathrm{C}$ for $14 \mathrm{~h}$ for degassing treatment before measurement. The specific surface area and pore size distribution of the samples were obtained from the $\mathrm{N}_{2}$ adsorption desorption isotherm by the Brunauer-Emmett-Teller (BET) method and the quenched solid density functional theory (QSDFT) method [28], respectively. The total pore volume was obtained at a relative pressure of $P / P_{0}=0.99$.

\section{Results and Analysis}

Figure 2 shows the adsorption breakthrough curves of COS, COSC- 0 , and COSC-1 for cooking fumes. The penetration times of COS, COSC-0, and COSC-1 were 0.9, 2.1, and $4.1 \mathrm{~h}$, respectively, which indicated that the effective action time of COSC- 1 was the longest among the tested materials. Figure 3 illustrates the adsorption quantity of COS, COSC- - , and COSC- 1 for cooking fumes. The adsorption quantities of COS, COSC-0, and COSC-1 for cooking fumes were $6.43,22.58$, and $44.04 \mathrm{mg} / \mathrm{g}$, respectively, which showed that the adsorption quantity of COSC -1 was the largest. Thus, COSC-1 demonstrated better adsorption properties than COS and COSC-0.



Figure 2. Adsorption breakthrough curves of different adsorbents for cooking fumes (GHSV: 4300/h, $\left.T=25^{\circ} \mathrm{C}, \mathrm{C}_{0}=90 \mathrm{mg} / \mathrm{m}^{3}, H=30 \mathrm{~cm}\right)$.

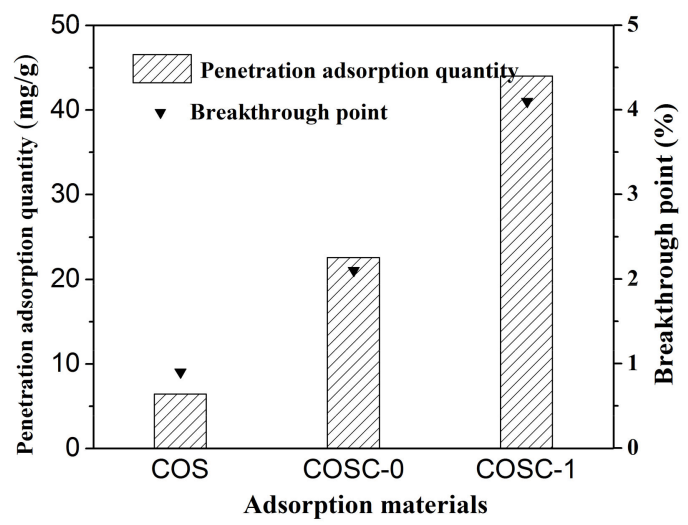

Figure 3. Adsorption quantity of different adsorbents for cooking fumes (GHSV: 4300/h, T=25 ${ }^{\circ} \mathrm{C}$, $\left.C_{0}=90 \mathrm{mg} / \mathrm{m}^{3}, H=30 \mathrm{~cm}\right)$. 
GC-MS analysis was conducted to identify the adsorption component of cooking fumes by COS, COSC- 0 , and COSC -1 . The detected species and their relative abundances are listed in Table 1 and Figure 4. The results showed that the main compositions of cooking fumes were aldehydes and substituent olefins. Cheng et al. [29] carried out a systematic study on aldehydes and ketones in the exhausts of eight Beijing restaurants, and found that the concentrations of aldehydes and ketones (C1-C9) were in the range of 115.47-1035.99 $\mu \mathrm{g} . \mathrm{m}^{-3}$ and the percentages of $\mathrm{C} 1-\mathrm{C} 3$ were above $40 \%$. Compared with COS and COSC-0, COSC-1 demonstrated the best adsorption capacity for all the components of cooking fumes, as shown in Table 1, which was due to the dominant chemical adsorption performance resulting from the strong influence of the Fenton's reagent. However, COS, COSC-0, and COSC- 1 exhibited a similar and better adsorption capacity for aldehydes than that for substituted olefins, such as p-propenyl phenyl methyl ether, $\mathrm{N}$ benzyl-allyl amine, 1,5-diphenyl-3-(2-ethyl benzene)-2-amylene, timnodonic acid, and 2-methyl-6-benzene-1,6-heptyl diene. This is because aldehyde compounds are a class of volatile organic compounds with strong chemical reactivity, which were easily adsorbed by COS, COSC-0, and COSC- 1 .

Table 1. Results of the cooking fume pollutants treated by different absorbents.

\begin{tabular}{|c|c|c|c|c|c|c|}
\hline \multirow{2}{*}{ No. } & \multirow{2}{*}{$t(\min )$} & \multirow{2}{*}{ Name of Chemical Compound } & \multirow{2}{*}{ Molecular Formula } & \multicolumn{3}{|c|}{ Removal Rate (\%) } \\
\hline & & & & COS & COSC-0 & COSC-1 \\
\hline 1 & 3.189 & 2, 7-dimethyl-1-octanol & $\mathrm{C}_{10} \mathrm{H}_{22} \mathrm{O}$ & 100 & 100 & 100 \\
\hline 2 & 4.965 & n-heptaldehyde & $\mathrm{C}_{7} \mathrm{H}_{14} \mathrm{O}$ & 100 & 100 & 100 \\
\hline 3 & 6.263 & (2Z)-Heptenal & $\mathrm{C}_{7} \mathrm{H}_{12} \mathrm{O}$ & 100 & 100 & 100 \\
\hline 4 & 7.051 & 2-Pentylfuran & $\mathrm{C}_{9} \mathrm{H}_{14} \mathrm{O}$ & 40 & 67 & 100 \\
\hline 5 & 7.421 & Octanal & $\mathrm{C}_{8} \mathrm{H}_{16} \mathrm{O}$ & 100 & 100 & 100 \\
\hline 6 & 8.949 & (E)-2-Octena & $\mathrm{C}_{8} \mathrm{H}_{14} \mathrm{O}$ & 100 & 100 & 100 \\
\hline 7 & 10.7 & 1-hexyl-1-cyclopentene & $\mathrm{C}_{11} \mathrm{H}_{20}$ & 67 & 48 & 100 \\
\hline 8 & 11.58 & p-propenyl phenyl methyl ether & $\mathrm{C}_{10} \mathrm{H}_{12} \mathrm{O}$ & 27 & 37 & 46 \\
\hline 9 & 11.8 & trans-2-nonenal & $\mathrm{C}_{9} \mathrm{H}_{16} \mathrm{O}$ & 100 & 100 & 100 \\
\hline 10 & 14.58 & trans-2-decyl olefine aldehyde & $\mathrm{C}_{10} \mathrm{H}_{18} \mathrm{O}$ & 100 & 100 & 100 \\
\hline 11 & 15.35 & 2-octyl-tetrahydro-furan & $\mathrm{C}_{12} \mathrm{H}_{20} \mathrm{O}$ & 100 & 100 & 100 \\
\hline 12 & 16.11 & 2, 4-decadienal & $\mathrm{C}_{10} \mathrm{H}_{16} \mathrm{O}$ & 100 & 100 & 100 \\
\hline 13 & 17.27 & 2-undecenal & $\mathrm{C}_{11} \mathrm{H}_{20} \mathrm{O}$ & 100 & 100 & 100 \\
\hline 14 & 20.78 & N-benzal-allyl amine & $\mathrm{C}_{10} \mathrm{H}_{11} \mathrm{~N}$ & 31 & 46 & 53 \\
\hline 15 & 26.92 & 1, 2-diphenyl cyclopropane & $\mathrm{C}_{15} \mathrm{H}_{14}$ & 22 & 31 & 43 \\
\hline 16 & 27.93 & linalyl isobutyrate & $\mathrm{C}_{14} \mathrm{H}_{24} \mathrm{O}_{2}$ & 100 & 100 & 100 \\
\hline 17 & 28.72 & 3-DNA-estradiol & $\mathrm{C}_{18} \mathrm{H}_{24} \mathrm{O}$ & 27 & 28 & 44 \\
\hline 18 & 29.08 & 1, 5-diphenyl-3-(2-ethyl benzene)-2-amylene & $\mathrm{C}_{25} \mathrm{H}_{26}$ & 30 & 40 & 50 \\
\hline 19 & 29.42 & timnodonic acid & $\mathrm{C}_{20} \mathrm{H}_{30} \mathrm{O}_{2}$ & 22 & 33 & 45 \\
\hline 20 & 30.41 & 5, 7-dodecane acetylene 2-1, 12-dio & $\mathrm{C}_{12} \mathrm{H}_{18} \mathrm{O}_{2}$ & 29 & 36 & 52 \\
\hline 21 & 31.02 & [(2, 3-diphenyl propyl) methyl]-phenyl sulfur & $\mathrm{C}_{22} \mathrm{H}_{20} \mathrm{OS}$ & 26 & 100 & 100 \\
\hline 22 & 33.34 & 2-methyl-6-benzene-1, 6-heptyl diene & $\mathrm{C}_{14} \mathrm{H}_{18}$ & 41 & 52 & 64 \\
\hline
\end{tabular}

Annotation: 1-22 are the tested pollutants during the process of cooking fume suction.

To further investigate the adsorption behavior of COS, COSC- 0 , and COSC- 1 , the morphology and structure of COS, COSC- 0 , and COSC -1 were characterized by specific surface area and pore analyzers, SEM, and FTIR.

$\mathrm{N}_{2}$ of the adsorption-desorption isotherms obtained at $77.4 \mathrm{~K}$ of COS, COSC-0, and COSC- 1 is shown in Figure 5. The figure shows that the isotherms of COSC- 0 and COSC-1 belonged to capillary condensation (IV) according to the definition of IUPAC [30]. The adsorption capacity increased with the increase in relative pressure, and the adsorption volume of $\mathrm{N}_{2}$ sharply ascended when the relative pressure reached 1.0, which indicated the existence of mesoporous and macroporous pores in those adsorbents [31]. Figure 6 shows the pore size distribution of COSC- 0 and COSC -1 . The pore size of COSC- 0 and COSC-1 exhibited centralized distribution, and the pore apertures were mainly distributed in the range of 3.2-4.5 nm, which confirmed the mesoporous structure of COSC-0 and 
COSC-1. It has been confirmed that components with a large molecular diameter are always more easily absorbed by adsorbents with large apertures than their counterparts. The components of aldehydes and substituent olefins from cooking fumes have a macromolecular structure, which means that they are easily absorbed by COSC-0 and COSC-1 with mesoporous structures.

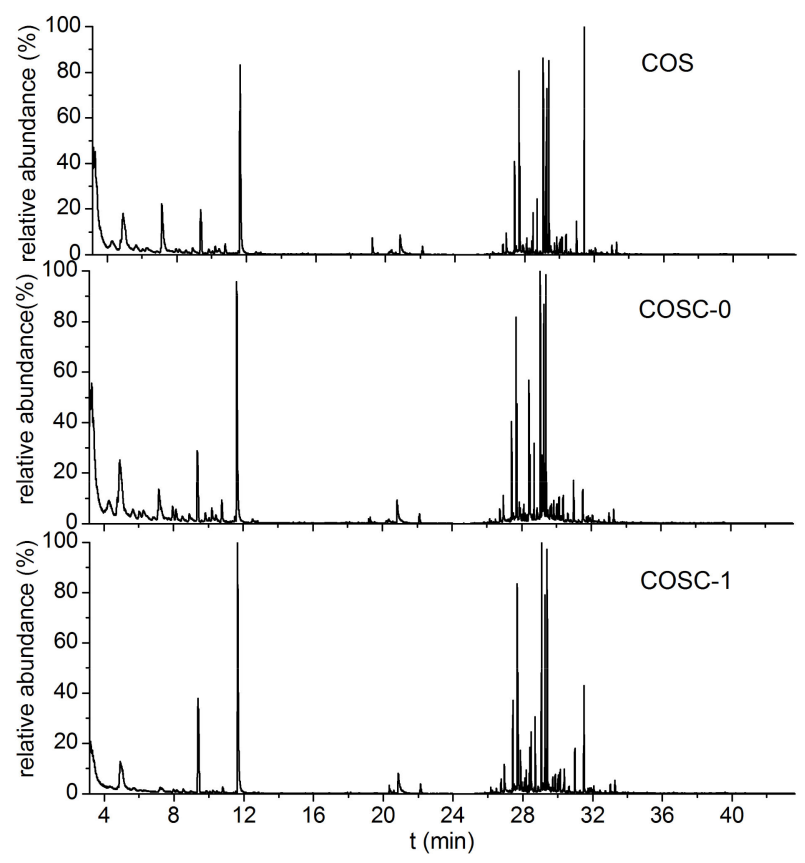

Figure 4. Total ionic chromatogram of absorbent components after treating cooking fumes.

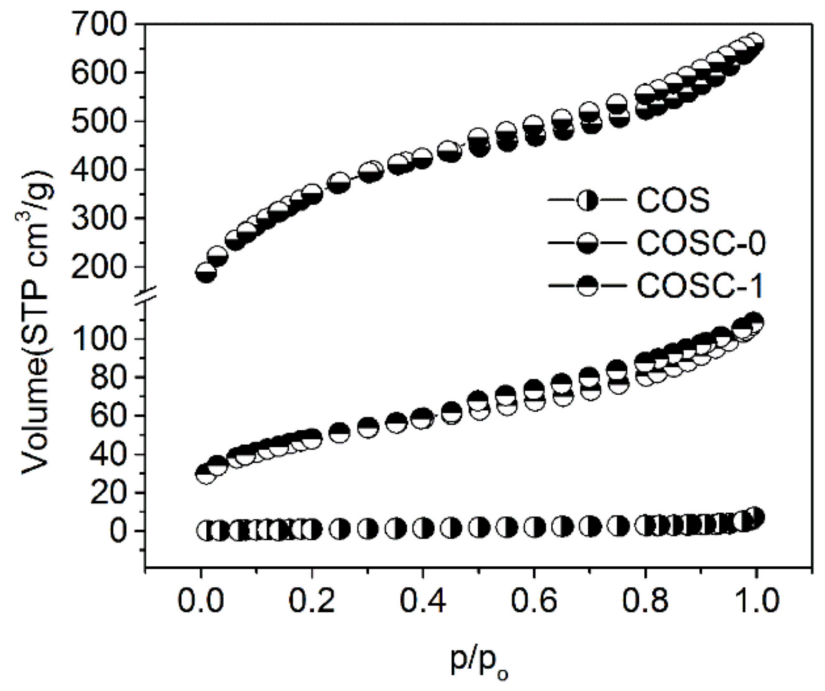

Figure 5. Nitrogen adsorption-desorption isotherm of COS, COSC-0, and COSC-1.

Table 2 shows the specific surface areas and porous structures of COSC- 0 and COSC-1. Compared with COSC-0, COSC-1 showed a decrease in the specific surface areas and pore volumes and a slight increase in aperture, because part of the porous microstructure of COSC was collapsed by the oxidation of $\mathrm{H}_{2} \mathrm{O}_{2}$ after treatment with Fenton's reagent. Moreno-Castilla et al. [32] and Bandosz Teresa et al. [33] also found that $\mathrm{H}_{2} \mathrm{O}_{2}$ modification can result in the reduction in the specific surface area of $A C$ to different degrees. Figure 7 shows the SEM images of COS, COSC-0, and COSC-1. Large quantities of substances were adsorbed on the surface or filled in the pores of COSC-1 (Figure 7(c1,c2)), which proved 
the decrease in specific surface areas and pore volumes of COSC-1.

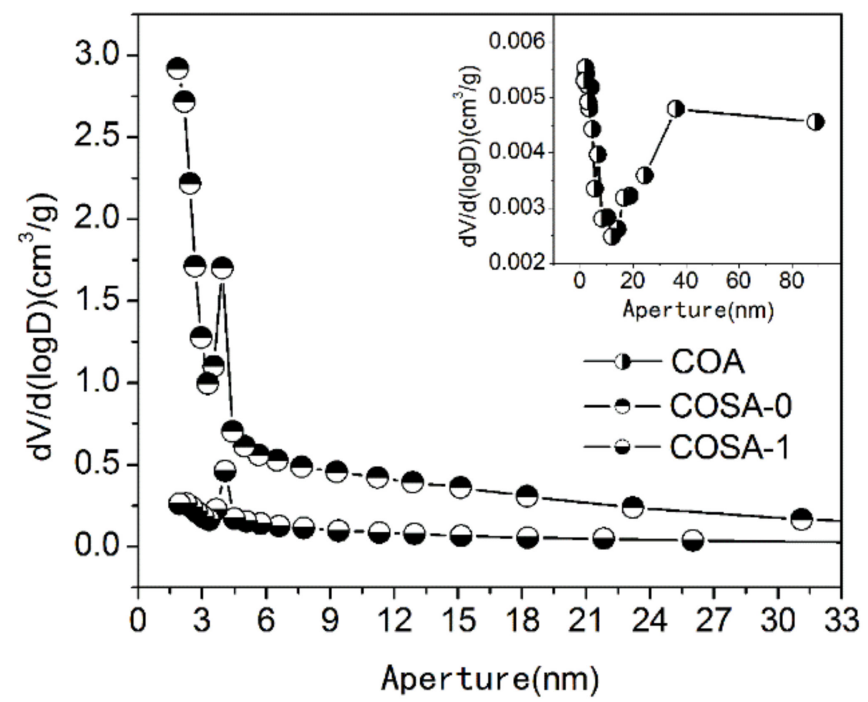

Figure 6. Pore size distribution of COS, COSC-0, and COSC-1.

Table 2. Specific surface area and pore structures of COSC-0 and COSC-1.

\begin{tabular}{ccc}
\hline Samples & COSC-0 & COSC-1 \\
\hline$S_{B E T} /\left(\mathrm{m}^{2} / \mathrm{g}\right)$ & 1245 & 934 \\
$V_{\text {total }} /\left(\mathrm{cm}^{3} / \mathrm{g}\right)$ & 1.02 & 0.69 \\
$D_{p} /(\mathrm{nm})$ & 3.284 & 4.021 \\
\hline
\end{tabular}

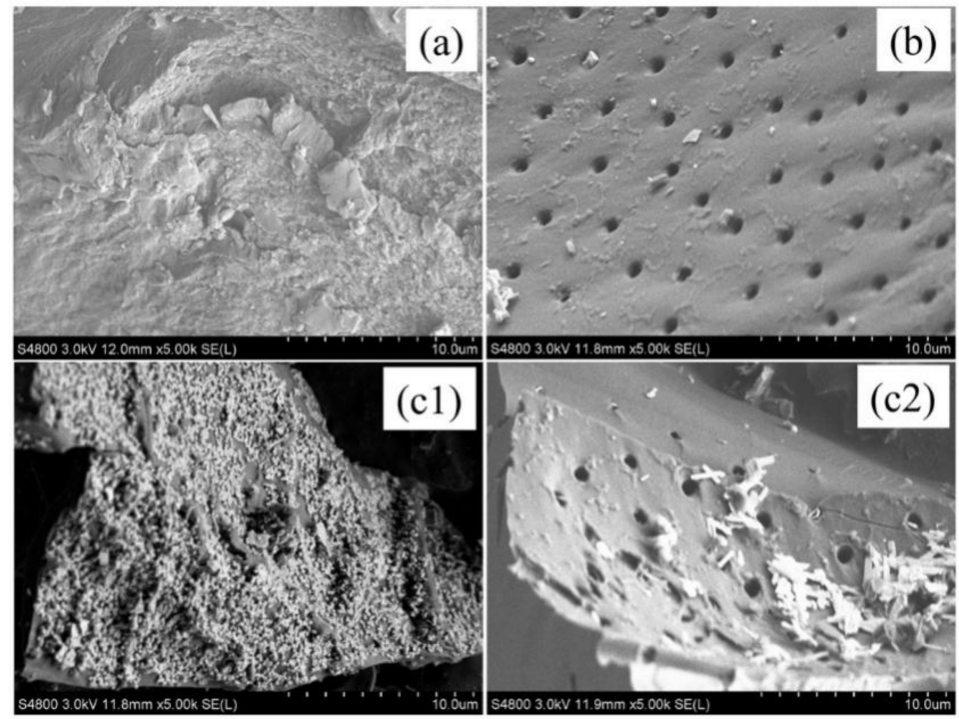

Figure 7. SEM images of the three kinds of materials. COS: (a); COSC-0: (b); COSC-1: (c1), (c2).

Figure 8 shows the FTIR spectra of COSC-0 and COSC-1. The broad and strong absorption peak at $3417 \mathrm{~cm}^{-1}$ was related to the stretching vibration of $-\mathrm{OH}$. The absorption peak at $1620 \mathrm{~cm}^{-1}$ was the flexural vibration peak of hydroxyl (the physical absorbed water), which indicated that some water molecules were introduced into the surface and the pores of adsorbent in the form of absorbed water. The absorption bands, which were formed by skeletal vibrations, were observed at 1714, 1620, 1384, 1036, 875, and $592 \mathrm{~cm}^{-1}$. The peak at $1714 \mathrm{~cm}^{-1}$ corresponded to the stretching vibration peak of $\mathrm{C}=\mathrm{O}$ in the carbonyl 
and carboxyl [34]. The steep peak at $1384 \mathrm{~cm}^{-1}$ was the stretching vibration peak of -NO. The broad and strong vibrations at 1036 and $1116 \mathrm{~cm}^{-1}$ were the symmetrical stretching vibrations of $\mathrm{S}=\mathrm{O}$ bonds in $\mathrm{SO}_{4}{ }^{2-}$. The peak at $875 \mathrm{~cm}^{-1}$ corresponded to the symmetrical vibration [35] of P-O-P in polyphosphate. The peak at $592 \mathrm{~cm}^{-1}$ belonged to the lattice vibration of cations $\left(\mathrm{Fe}^{2+}, \mathrm{Fe}^{3+}, \mathrm{Al}^{3+}\right.$, and $\left.\mathrm{Mg}^{2+}\right)$ [36], whose location was the same as the stretching vibration of Fe-O. As shown in Figure 8, the new peak at $1714 \mathrm{~cm}^{-1}$ appeared and the peak at $592 \mathrm{~cm}^{-1}$ became apparent in the sample of COSC-1, indicating that a large number of carbonyl and carboxyl groups and Fe ions generated after COSC-0 were modified by Fenton's reagent. Compared with COSC-0, the absorption peaks of the carbonyl and carboxyl groups in COSC-1 were stronger and broader. Thus, COSC-1 demonstrated the best absorption performance for organic contaminants in cooking fumes among the tested materials.

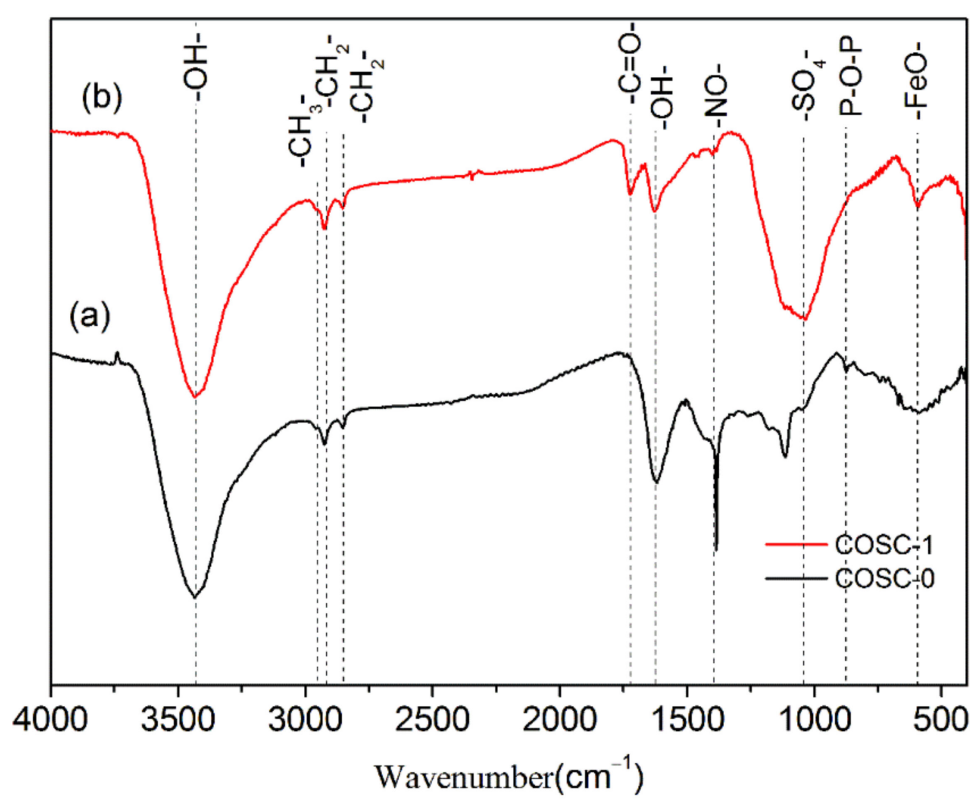

Figure 8. FTIR spectrum of COSC-0 (a) and COSC-1 (b).

The large number of carbonyl and carboxyl groups generated on the surface of COSC-1 resulted from the action of Fenton's reagent. The catalytic effect of $\mathrm{Fe}^{2+}$ and $\mathrm{Fe}^{3+}$ formed in the Fenton system was favored in the conversion of $\mathrm{H}_{2} \mathrm{O}_{2}$ into $\mathrm{HO}$. and $\mathrm{HOO}$, as shown in Equations (3) and (4). HO radicals have strong addition reaction and oxidation capacity due to their electron-deficient group and high electric potential (+2.8 V) [11,37,38]. Therefore, radicals of $\mathrm{HO} \cdot$ or $\mathrm{HOO}$. could attack unsaturated double bonds and defects on the surface of COSC-1 and addition reactions could occur, which resulted in the carbonyl and carboxyl functional groups forming on the surface of COSC-1. In addition, $\mathrm{HO}$. can further oxidize unstable $-\mathrm{CH}_{2} \mathrm{OH}$ and $-\mathrm{CHOH}$ - functional groups into carboxyl groups on the surface of COSC-1 $[39,40]$. Thus, the surface modification of COSC- 0 was realized, and COSC-1 with a large number of carbonyl and carboxyl groups was formed.

$$
\begin{aligned}
& \mathrm{Fe}^{2+}+\mathrm{H}_{2} \mathrm{O}_{2} \rightarrow \mathrm{Fe}^{3+}+\mathrm{HO}+\mathrm{OH}^{-} \\
& \mathrm{Fe}^{3+}+\mathrm{H}_{2} \mathrm{O}_{2} \rightarrow \mathrm{Fe}^{2+}+\mathrm{HOO}+\mathrm{H}^{+}
\end{aligned}
$$

Compared with COSC-0, COSC-1 presented better adsorption capacity because it is rich in carbonyl and carboxyl groups, which can react with carboxylic acids and alcohols from cooking fumes to improve the adsorption capacity of COSC-1. Moreover, during the preparation of COSC-1, some substances, such as $\mathrm{HO}, \mathrm{Fe}^{3+}, \mathrm{Fe}^{2+}$, and $\mathrm{H}_{2} \mathrm{O}_{2}$, may remain on the surface or the inner wall of the pore of COSC-1. These substances can oxidize and 
decompose most of the oil fume pollutants adsorbed on the surface of COSC-1, thereby increasing the adsorption capacity of COSC-1.

Table 1 shows that all of the adsorption capacities of COS, COSC-0, and COSC-1 for aldehydes were $100 \%$, which indicated that aldehydes could easily be adsorbed by COS, COSC- 0 , and COSC- 1 . According to the similarity principle that similar substance is more likely to be dissolved by each other, aldehydes were easily compatible with carbonyl and carboxyl groups on the surface of COS, COSC-0 and COSC- 1 due to their similar polarities [41,42]. By contrast, the polarity of functional groups $(-\mathrm{C}=\mathrm{C}-$ of olefins was weaker than that of the functional groups on the surface of COS, COSC-0 and COSC- 1 . Therefore, the adsorption performance of COS, COSC- 0 , and COSC- 1 on olefins was weaker than that on aldehydes.

Recently, Yu et al. [43] reported a novel ferrisilicate MEL zeolite applied for the removal of non-methane hydrocarbon (NMHC) from cooking oil fumes (COFs). A comparison of the performance on the adsorption of cooking fumes between COSC with ferrisilicate MEL zeolites was made, as shown in Table 3. COSC-1 presented the best adsorption performance for cooking fumes, which indicates that COSC-1 is a good material for cooking fume purification.

Table 3. Adsorption performance of different adsorbents for cooking fumes.

\begin{tabular}{ccccc}
\hline Adsorbent & $S_{B E T} /\left(\mathbf{m}^{2} / \mathbf{g}\right)$ & $V_{\text {total }} /\left(\mathbf{c m}^{3} / \mathbf{g}\right)$ & $P A Q /(\mathbf{m g} / \mathbf{g})$ & References \\
\hline COSC-0 & 1244.7 & 1.02 & 6.43 & This study \\
\hline COSC-1 & 933.5 & 0.69 & 22.58 & This study \\
\hline Sam-SiFe (II) & 388.0 & 0.23 & 4.468 & {$[43]$} \\
\hline$\underline{\text { Sam-SiFe (III) }}$ & 411.4 & 0.23 & 3.659 & {$[43]$} \\
\hline$\underline{\text { Sam-SiAl }}$ & 403.6 & 0.23 & 2.781 & {$[43]$} \\
\hline
\end{tabular}

PAQ: penetration adsorption quantities. Sam-SiFe (II), Sam-SiFe (III): Fe-containing zeolites. Sam-SiAl: Alcontaining zeolites.

\section{Conclusions}

A cheap adsorbent (COSC-1), which was activated by phosphoric acid and then modified by Fenton's reagent from COSC, has been successfully prepared, and the adsorption properties for cooking fume were studied. Results showed that COSC-1 was the best adsorbent compared with COS and COSC-0. The superior adsorption properties of COSC-1 were due to the large number of carbonyl and carboxyl groups generated on the surface of COSC- 1 from the action of Fenton's reagent. The adsorption effects of COSC- 1 on different types of pollutants of cooking fume were analyzed based on the similar compatibility principle. The adsorption effect of COSC-1 on strong polarity functional groups was much higher than that on weak polar groups. COSC- 1 also exhibited a far better performance on the adsorption of cooking fumes compared with ferrisilicate MEL zeolites. This work provides a theoretical basis for the application of COSC adsorption technology in the treatment of cooking fumes.

Author Contributions: Conceptualization, D.L.; methodology, W.S.; software, J.G.; formal analysis, D.L.; investigation, D.L., W.S., J.G., B.D. and R.Y.; resources, D.L.; writing-Original draft preparation, D.L.; writing-Review and editing, R.Y., B.D. and D.L.; supervision, B.D. and R.Y.; funding acquisition, R.Y. All authors have read and agreed to the published version of the manuscript.

Funding: This research received no external funding.

Institutional Review Board Statement: Not applicable.

Informed Consent Statement: Not applicable.

Data Availability Statement: Data is contained within the article. 
Acknowledgments: The work was financially supported by Undergraduate Innovation Fund of Northwest A\&F University.

Conflicts of Interest: The authors declare no conflict of interest.

\section{References}

1. Dong, S.; Wu, J.; Liu, G.; Zhang, B.; Zheng, M. Unintentionally produced dioxin-like polychlorinated biphenyls during cooking. Food Control 2011, 22, 1797-1802. [CrossRef]

2. Jiang, X.; Zhu, S.; Wu, Y.; Huai, H. The effects of cooking oil fume condensates (COFCs) on the vegetative growth of Salvinia natans (L.) All. J. Hazard. Mater. 2009, 172, 240-246. [CrossRef]

3. Katragadda, H.R.; Fullana, A.; Sidhu, S.; Carbonell-Barrachina, Á.A. Emissions of volatile aldehydes from heated cooking oils. Food Chem. 2010, 120, 59-65. [CrossRef]

4. Yin, Z.; Cui, Z.; Guan, P.; Li, X.; Wu, W.; Ren, Y.; Zhou, B. Interaction between polymorphisms in pre-MiRNA genes and cooking oil fume exposure on the risk of lung cancer in Chinese non-smoking female population. PLoS ONE 2015, 10, e0128572. [CrossRef] [PubMed]

5. Ren, Y.; Yin, Z.; Li, K.; Wan, Y.; Li, X.; Wu, W.; Guan, P.; Zhou, B. TGF $\beta-1$ and TGFBR2 polymorphisms, cooking oil fume exposure and risk of lung adenocarcinoma in Chinese nonsmoking females: A case control study. BMC Med. Genet. 2015, 16, 1-6. [CrossRef] [PubMed]

6. Couraud, S.; Zalcman, G.; Milleron, B.; Morin, F.; Souquet, P.-J. Lung cancer in never smokers-A review. Eur. J. Cancer 2012, 48, 1299-1311. [CrossRef]

7. Xue, X.; Yin, Z.; Lü, Y.; Zhang, H.; Yan, Y.; Zhao, Y.; Li, X.; Cui, Z.; Yu, M.; Yao, L.; et al. The Joint Effect of hOGG1, APE1, and ADPRT Polymorphisms and Cooking Oil Fumes on the Risk of Lung Adenocarcinoma in Chinese Non-Smoking Females. PLoS ONE 2013, 8, e71157. [CrossRef]

8. Cheng, H.-H.; Hsieh, C.-C. Integration of chemical scrubber with sodium hypochlorite and surfactant for removal of hydrocarbons in cooking oil fume. J. Hazard. Mater. 2010, 182, 39-44. [CrossRef]

9. Wang, J.; Liao, C.; Chen, Y.; Cao, H.; Liu, Z.; Gong, M.; Chen, Y. Low-temperature catalytic combustion of cooking fume over $\mathrm{Pt} /$ gamma- $\mathrm{Al}_{2} \mathrm{O}_{3} / \mathrm{Ce}_{0.5}-\mathrm{XZr}_{0.5}-\mathrm{xMn}_{2} \mathrm{xO}_{2}$ monolithic catalyst. Chin. J. Catal. 2010, 31, 404-408.

10. Wu, M.-T.; Lee, L.-H.; Ho, C.-K.; Wu, S.-C.; Lin, L.-Y.; Cheng, B.-H.; Liu, C.-L.; Yang, C.-Y.; Tsai, H.-T.; Wu, T.-N. Environmental exposure to cooking oil fumes and cervical intraepithelial neoplasm. Environ. Res. 2004, 94, 25-32. [CrossRef]

11. Boehm, H. Surface oxides on carbon and their analysis: A critical assessment. Carbon 2002, 40, 145-149. [CrossRef]

12. Suzuki, R.; Andrade, A.; Sousa, J.; Rollemberg, M. Preparation and characterization of activated carbon from rice bran. Bioresour. Technol. 2007, 98, 1985-1991. [CrossRef]

13. Oh, G.H.; Park, C.R. Preparation and characteristics of rice-straw-based porous carbons with high adsorption capacity. Fuel 2002, 81, 327-336. [CrossRef]

14. Ahmedna, M.; Marshall, W.; Rao, R. Production of granular activated carbons from select agricultural by-products and evaluation of their physical, chemical and adsorption properties1Louisiana Agricultural Experiment Station manuscript 99-21-0066.1. Bioresour. Technol. 2000, 71, 113-123. [CrossRef]

15. Yang, T.; Lua, A.C. Characteristics of activated carbons prepared from pistachio-nut shells by physical activation. J. Colloid Interface Sci. 2003, 267, 408-417. [CrossRef]

16. Lua, A.C.; Yang, T.; Guo, J. Effects of pyrolysis conditions on the properties of activated carbons prepared from pistachio-nut shells. J. Anal. Appl. Pyrolysis 2004, 72, 279-287. [CrossRef]

17. Ahmadpour, A.; Do, D. The preparation of activated carbon from macadamia nutshell by chemical activation. Carbon 1997, 35, 1723-1732. [CrossRef]

18. Ahmedna, M.; E Marshall, W.; Husseiny, A.A.; Rao, R.M.; Goktepe, I. The use of nutshell carbons in drinking water filters for removal of trace metals. Water Res. 2004, 38, 1062-1068. [CrossRef]

19. Savova, D.; Apak, E.; Ekinci, E.; Yardim, F.; Petrov, N.; Budinova, T.; Razvigorova, M.; Minkova, V. Biomass conversion to carbon adsorbents and gas. Biomass Bioenergy 2001, 21, 133-142. [CrossRef]

20. Marcilla, A.; García-García, S.; Asensio, M.; Conesa, J. Influence of thermal treatment regime on the density and reactivity of activated carbons from almond shells. Carbon 2000, 38, 429-440. [CrossRef]

21. Aygün, A.; Yenisoy-Karakaş, S.; Duman, I. Production of granular activated carbon from fruit stones and nutshells and evaluation of their physical, chemical and adsorption properties. Microporous Mesoporous Mater. 2003, 66, 189-195. [CrossRef]

22. Minkova, V.; Razvigorova, M.; Bjornbom, E.; Zanzi, R.; Budinova, T.; Petrov, N. Effect of water vapour and biomass nature on the yield and quality of the pyrolysis products from biomass. Fuel Process. Technol. 2001, 70, 53-61. [CrossRef]

23. Minkova, V.; Marinov, S.; Zanzi, R.; Björnbom, E.; Budinova, T.; Stefanova, M.; Lakov, L. Thermochemical treatment of biomass in a flow of steam or in a mixture of steam and carbon dioxide. Fuel Process. Technol. 2000, 62, 45-52. [CrossRef]

24. Jin, X. Bioactivities of water-soluble polysaccharides from fruit shell of Camellia oleifera Abel: Antitumor and antioxidant activities. Carbohydr. Polym. 2012, 87, 2198-2201. [CrossRef]

25. Sun, K.; Jiang, J.C.; Cui, D.D. Preparation of activated carbon with highly developed mesoporous structure from Camellia oleifera shell through water vapor gasification and phosphoric acid modification. Biomass Bioenergy 2011, 35, 3643-3647. 
26. Zheng, Z.; Zhao, H.; Lin, X.; Yang, J.; Shi, R. Preparation of activated carbon from Camellia oleifera shell and its application to adsorption of hexavalent chromium from aqueous solution: Kinetics, equilibrium, and thermodynamics. Desalin Water Treat. 2020, 198, 170-179. [CrossRef]

27. Mei, L.; Qiao, H.; Ke, F.; Peng, C.; Hou, R.; Wan, X.; Cai, H. One-step synthesis of zirconium dioxide-biochar derived from Camellia oleifera seed shell with enhanced removal capacity for fluoride from water. Appl. Surf. Sci. 2020, 509, 144685. [CrossRef]

28. Gor, G.Y.; Thommes, M.; Cychosz, K.A.; Neimark, A.V. Quenched solid density functional theory method for characterization of mesoporous carbons by nitrogen adsorption. Carbon 2012, 50, 1583-1590. [CrossRef]

29. Cheng, J.-C.; Cui, T.; He, W.-Q.; Nie, L.; Wang, J.-L.; Pan, T. Pollution Characteristics of Aldehydes and Ketones Compounds in the Exhaust of Beijing Typical Restaurants. Huanjing Kexue 2015, 36, 2743-2749.

30. Zheng, S.; Luo, Y.; Zhang, K.; Liu, H.; Hu, G.; Qin, A. Nitrogen and phosphorus co-doped mesoporous carbon nanosheets derived from bagasse for lithium-ion batteries. Mater. Lett. 2021, 290, 129459. [CrossRef]

31. Fan, Y.H.; Yu, N.H.; Deng, L.Y. Preparation of High Mesoporous Activated Carbon from Camellia oleifera Shell. J. Northwest For. Univ. 2019, 34, 187-194.

32. Morenocastilla, C.; Ferrogarcia, M.A.; Joly, J.P.; Bautistatoledo, I.; Carrascomarin, F.; Riverautrilla, J. Activated Carbon Surface Modifications by Nitric Acid, Hydrogen Peroxide, and Ammonium Peroxydisulfate Treatments. Langmuir 1995, 11, 4386-4392. [CrossRef]

33. Bandosz, T.J.; Jagiełło, J.; Schwarz, J.A.; Krzyzanowski, A. Effect of Surface Chemistry on Sorption of Water and Methanol on Activated Carbons. Langmuir 1996, 12, 6480-6486. [CrossRef]

34. Yao, R.P.; Zhang, M.J.; Yang, J.; Yi, D.L.; Xu, J.; Deng, F.; Yue, Y.; Ye, C.H. Preparation of $\mathrm{SO}_{3} /$ gamma- $\mathrm{Al}_{2} \mathrm{O}_{3}$ solid acid catalyst and characterization of its structure and acidity. Acta Chim. Sin. 2005, 64, 269-273.

35. Krehula, S.; Music, S. Influence of ruthenium ions on the precipitation of alpha-FeOOH, alpha- $\mathrm{Fe}_{2} \mathrm{O}_{3}$ and $\mathrm{Fe}_{3} \mathrm{O}_{4}$ in highly alkaline media. J. Alloy. Compd. 2006, 416, 284-290. [CrossRef]

36. Sudakar, C.; Subbanna, G.N.; Kutty, T.R.N. Synthesis of acicular hydrogoethite $(\alpha-\mathrm{FeOOH} \times \mathrm{xH} 2 \mathrm{O} ; 0.1<\mathrm{x}<0.22)$ particles using morphology controlling cationic additives and magnetic properties of maghemite derived from hydrogoethite. J. Mater. Chem. 2001, 12, 107-116.

37. You, J.H.; Chiang, H.L.; Chiang, P.C. Comparison of adsorption characteristics for VOCs on activated carbon and oxidized activated carbon. Environ. Prog. 1994, 13, 31-36. [CrossRef]

38. Pan, B.; Xing, B. Adsorption Mechanisms of Organic Chemicals on Carbon Nanotubes. Environ. Sci. Technol. 2008, 42, 9005-9013. [CrossRef]

39. Cong, Y.; Wu, Z. Electrocatalytic Generation of Radical Intermediates over Lead Dioxide Electrode Doped with Fluoride. J. Phys. Chem. C 2007, 111, 3442-3446. [CrossRef]

40. Ma, N.; Tian, Y.-J.; Yang, G.-P.; Xie, X.-Y. Modification of activated carbon fiber for electro-Fenton degradation of phenol. Huanjing kexue 2014, 35, 2627-2632.

41. Trinh, Q.H.; Lee, S.B.; Mok, Y.S. Removal of ethylene from air stream by adsorption and plasma-catalytic oxidation using silver-based bimetallic catalysts supported on zeolite. J. Hazard. Mater. 2015, 285, 525-534. [CrossRef] [PubMed]

42. Xu, X.; Wang, P.; Xu, W.; Wu, J.; Chen, L.; Fu, M.; Ye, D. Plasma-catalysis of metal loaded SBA-15 for toluene removal: Comparison of continuously introduced and adsorption-discharge plasma system. Chem. Eng. J. 2016, 283, 276-284. [CrossRef]

43. Yu, Q.; Feng, Y.; Tang, X.; Yi, H.; Zhao, S.; Gao, F.; Zhou, Y.; Zhang, Y.; Zhuang, R. A novel ferrisilicate MEL zeolite with bi-functional adsorption/catalytic oxidation properties for non-methane hydrocarbon removal from cooking oil fumes. Microporous Mesoporous Mater. 2020, 309, 110509. [CrossRef] 